\title{
A techno-economic comparison of various process options for the production of 1,1-diethoxy butane
}

\author{
Ion Agirre a,b \\ María Belén Güemez a \\ Anatolie Motelica ${ }^{b}$ \\ Henk M. vanVeen ${ }^{b}$ \\ Jaap F. Vente ${ }^{b}$ \\ Pedro L. Arias ${ }^{a}$ \\ ${ }^{a}$ Chemical and Environmental Engineering Department, Engineering Faculty of Bilbao (UPV-EHU). \\ Alameda Urquijo s/n, 48013 Bilbao, Spain \\ ${ }^{b}$ Energy research Centre of the Netherlands, P.O. Box 1, 1755 ZG Petten, the Netherlands
}

Published in J Chem Technol Biotechnol 2012; 87: 943-954 


\title{
A techno-economic comparison of various process options for the production of 1,1-diethoxy butane
}

\author{
Ion Agirre, ${ }^{\mathrm{a}, \mathrm{b} *}$ María Belén Güemez, ${ }^{\mathrm{a}}$ Anatolie Motelica, ${ }^{\mathrm{b}}$ Henk M. van \\ Veen, ${ }^{b}$ Jaap F. Vente ${ }^{b}$ and Pedro L. Arias ${ }^{a}$
}

\begin{abstract}
BACKGROUND: Acetals can be considered important bio-based diesel additives. The production of most of these compounds, from an alcohol and an aldehyde, suffers from low conversion due to thermodynamic limitations. These limitations can be overcome through the removal of the by-product water. Previous studies showed that the in situ dehydration options of reactive distillation and pervaporation membrane reactor integration offer little advantage or at least not at reasonable unit dimensions. The aim of the present work is the development of a membrane based process and comparison with other alternatives (based on experimental data).

RESULTS: Three different membrane processes were developed. The one in which the reaction mixture is recycled over a first dehydration membrane module and subsequently through a simple distillation column, was found to give the highest overall conversion (100\%) at low recycle rates and reasonable membrane area. This process was techno-economically compared with other possible alternatives: (1) a process based on a conventional tubular reactor and several distillation columns; and (2) a process based on reactive distillation.
\end{abstract}

CONCLUSIONS: Efficient water removal by membranes avoids possible azeotropes in downstream distillation units making them much simpler, reducing considerably the unit sizes and the energy demand ( $40 \%$ lower).

(c) 2012 Society of Chemical Industry

Keywords: acetal; biodiesel; membrane separation; modeling; HybSi

\section{NOTATION}

$A_{m} \quad$ Membrane area, $\mathrm{m}^{2}$

$\mathrm{A}_{\mathrm{t}} \quad$ Cross-sectional area, $\mathrm{m}^{2}$

$\mathrm{C}_{\mathrm{i}} \quad$ Concentration of each compound, $\mathrm{kmol} \mathrm{m}^{-3}$

$\mathrm{Cp}_{\mathrm{i}} \quad$ Specific heat for component $\mathrm{i}, \mathrm{kJ} \mathrm{kmol}^{-1}{ }^{\circ} \mathrm{C}^{-1}$

$\mathrm{d}_{\mathrm{o}} \quad$ Membrane tube diameter, $\mathrm{m}$

$d_{p} \quad$ Catalyst particle diameter, $m$

$f_{i} \quad$ Flux through the membrane for component $i$, $\mathrm{kmol} \mathrm{m}^{-2} \mathrm{~h}^{-1}$

$\mathrm{F}_{\mathrm{i}} \quad$ Molar flow rate in the shell side for component $\mathrm{i}$, $\mathrm{kmol} \mathrm{h}^{-1}$

J Total flow through the membrane, $\mathrm{kmol} \mathrm{m}^{-2} \mathrm{~h}^{-1}$

$\mathrm{k}_{1} \quad$ Kinetic constant for the forward reaction, $\left(\mathrm{m}^{3}\right)^{3} /\left(\mathrm{kmol}^{2} \cdot \mathrm{s} \cdot \mathrm{kgcat}\right)$

$\mathrm{k}_{2} \quad$ Kinetic constant for the reversible reaction, $\left(\mathrm{m}^{3}\right)^{2} /(\mathrm{kmol} \cdot \mathrm{s} \cdot \mathrm{kgcat})$

$\mathrm{L} \quad$ Reactor length, $\mathrm{m}$

$N \quad$ Number of membrane tubes

$\mathrm{P}_{\mathrm{F}} \quad$ Pressure in the feed side, bar

$p_{m} \quad$ Perimeter of total membrane tubes, $m$

$P_{P} \quad$ Permeate pressure, bar

$P_{i}^{\text {sat }} \quad$ Saturation pressure of component $i$, bar

$Q_{i} \quad$ Permeance of component $i, \mathrm{kmol} \mathrm{m}^{-2} \mathrm{~h}^{-1}$ bar $^{-1}$ )

Re Reynolds number
$\mathrm{R}_{\mathrm{v}} \quad$ Reactor volume, $\mathrm{dm}^{3}$

$\mathrm{T} \quad$ Temperature, $\mathrm{C}$

$\mathrm{t} \quad$ Time, $\mathrm{h}$

$v_{s} \quad$ Superficial velocity, $\mathrm{m} \mathrm{s}^{-1}$

w Catalyst loading in the reactor, $\mathrm{kg} \mathrm{m}^{-3}$

$x_{i} \quad$ Liquid molar fraction in the feed mixture

$y_{i} \quad$ Vapor molar fraction in the permeate mixture

$z \quad$ Normalized length $(0 \ldots 1)$

$\bar{\lambda} \quad$ The latent heat of the permeating fluid, $\mathrm{kJ} \mathrm{kmol}^{-1}$ $\Delta H_{r}^{298 K} \quad$ Enthalpy of reaction at $25^{\circ} \mathrm{C}, \mathrm{kJ} \mathrm{mol}^{-1}$

$\gamma_{i} \quad$ Activity coefficient for component i

$\varepsilon \quad$ Void fraction

$\mu \quad$ Dynamic viscosity of the liquid in the feedretentate side, $\mathrm{Pa} \mathrm{s}$

Correspondence to: Ion Agirre, Chemical and Environmental Engineering Department, Engineering Faculty of Bilbao (UPV-EHU). Alameda Urquijo $s / n$, 48013 Bilbao, Spain. E-mail: ion.agirre@ehu.es

a Chemical and Environmental Engineering Department, Engineering Faculty of Bilbao (UPV-EHU). Alameda Urquijo s/n, 48013 Bilbao, Spain

b Energy research Centre of the Netherlands, P.O. Box 1, 1755 ZG Petten, the Netherlands 
$\rho$

$\Phi$

$\Phi$

$\chi$
$\theta$

$v_{i}$

$v$

H10X

M10X

P10X

PV100 Pervaporation module

RD-T100 Reactive distillation column

S100 Splitter

T10X Distillation column

V100 Decanter

\section{INTRODUCTION}

Acetals are promising bio-based diesel additives. ${ }^{1}$ The miscibility of these oxygenated compounds with (bio)diesel is satisfactory, and the emission of particulate matter and nitrogen oxides, $\mathrm{NO}_{\mathrm{x}}$, can be lower using them as diesel additives. A light acetal as 1,1 diethoxy ethane has a flash point of $-21^{\circ} \mathrm{C}$, which is much lower than the required value of $55^{\circ} \mathrm{C}$. 1,1-diethoxy butane, a heavier acetal, fulfills all diesel specifications. It can be produced from ethanol and butanal and both can be obtained directly or indirectly from renewable feedstock via fermentation. Ethanol is a direct product of fermentation and butanal can be obtained from dehydrogenation or partial oxidation of $n$-butanol, which can also be a direct product of fermentation.

The synthesis of acetals typically occurs in a homogeneously catalyzed media in the presence of mineral acids such as $\mathrm{H}_{2} \mathrm{SO}_{4}, \mathrm{HF}, \mathrm{HCl}$ or p-toluene sulphonic acid. ${ }^{2-4}$ The intrinsic disadvantages of these catalysts are their corrosive nature and negative environmental effects. This has led to the study of alternative solid acid catalyst, and it is concluded that ion exchange resins show better performance than other catalysts. ${ }^{1}$

In recent years, there has been an increasing interest in process intensification. An example is the development of advanced processes where reaction and separation are combined in one single unit. These systems can overcome the thermodynamically limited equilibrium conversions that are typical for esterification or acetalization reactions. ${ }^{1,5-8}$ If water is a by-product, dehydration membrane reactors are among the most promising alternatives in this kind of reaction. The continuous in situ water removal from the reaction mixture shifts the reaction towards product formation. ${ }^{9-15}$ Saracco and Specchia, ${ }^{16}$ Coronas and Santamaría ${ }^{17}$ and Sanchez Marcano and Tsotsis ${ }^{18}$ were among the first to describe the advantages of a membrane reactor for different applications. More recently Drioli and Giorno ${ }^{19}$ have published an extensive work on membrane phenomena including state-of-theart on pervaporation membrane reactors.

The focus of most publications on this topic is lab scale batch studies and their modeling. ${ }^{14,15,20-24}$ However, some authors have studied different continuous processes. Zhu et al. ${ }^{9}$ performed continuous pervaporation experiments in a tubular pervaporation membrane reactor, and modeled esterification reactions using $\mathrm{H}_{2} \mathrm{SO}_{4}$ as a homogenous catalyst. De la Iglesia et al. ${ }^{25}$ also performed esterification reaction experiments in a continuous tubular reactor. Amberlyst 15 was used as catalyst, placed inside the membrane. Lim et al. ${ }^{11}$ studied different process configurations, and concluded that tubular membrane reactors lead to a better performance than stirred tank membrane reactors. Nemec et al. ${ }^{26}$ analyzed multifunctional tubular reactors with the catalyst particles in the annular region between the membrane and the module shell, and their results were not very promising.

Some time ago investigations of the different possibilities of 1,1-diethoxy butane (acetal) production at industrial scale were started. The first approach was by reactive distillation. It was found that thermodynamic limitations could be overcome, but due to the small volatility differences among the compounds the final conversions achieved were not as high as was desired. ${ }^{27}$ More recently, the development of membrane-based separation of water from the reaction mixture ${ }^{28}$ was considered. Different types of dehydration membranes can be used in the acetalization reaction for water removal. Many polymeric dehydration membranes show high separation factors (polyamide, chitosan, polyimide based membranes) ${ }^{29}$ but they offer really low fluxes. Other inorganic membranes like Pervatech amorphous silica membranes show high fluxes but long-term stability could be an issue. ${ }^{30}$ For this reason a hybrid inorganic-organic membrane (HybSi) was chosen for this application, having good separation factors and acceptable fluxes. HybSi is an organic-inorganic hybrid silica-based amorphous material. The hybrid nature of this material lies in the fact that each silicon atom is not only connected to oxygen atoms as in pure silica, but also to an organic fragment. The special feature of HybSi is that the organic fragments act as integral bridging fragments of the structure, and not just as end standing groups as in methylated silica. The result is a true hybrid silica pore network in which organic and inorganic fragments cooperate. More information can be found in an earlier report ${ }^{31}$ and at www.hybsi.com.

It was shown that in a batch membrane reactor, conversions are much higher than the thermodynamically-limited equilibrium conversion. These experiments have shown the feasibility of this approach, and this is a prime requirement for a viable process. However, the conclusion was that an integrated pervaporation membrane reactor using an Amberlyst catalyst and dehydration membranes was unlikely to be economically attractive because of the required unrealistic catalyst volume to membrane area ratio. ${ }^{32}$ In the current paper various new and alternative non-integrated methods of combining reaction and membrane separation are discussed, including setting up and discussing new possible flowsheets of the integrated process that could lead to a better process. Further, a techno-economic comparison between the best membrane-based alternative, the conventional, and a reactive distillation process is made.

\section{APPROACH}

The work starts with a membrane reactor case to identify and select the configuration with the highest conversion and lowest membrane area. The following scheme with uncoupled separation and reaction is evaluated first and compared with a combined reactor and membrane process:

1) Reactor followed by pervaporation in series

2) Reactor and pervaporation with a recycling loop

3) Reactor followed by pervaporation and distillation with a recycling loop

To keep consistency with previous studies on semi-pilot experiments on reactive distillation, ${ }^{27}$ a fixed flow rate of $7 \mathrm{Lh}^{-1}$ is 
considered. Further, the best resulting membrane-based configuration will be used for scale-up to an industrial scale and a techno-economic evaluation comparison with other technologies (a reaction + distillation case and a reactive distillation case) is made. The comparison is based on calculated conversion, required membrane area, sizing of unit operations, and costing, all of these calculated based on the estimated material and energy balances.

All the required kinetic data for the reaction were obtained experimentally. ${ }^{33}$ The component permeance data through the membrane were obtained from ethanol/butanal/1,1-diethoxy butane/water batch dehydration experiments, and validated using a batch model. ${ }^{28}$ All these data were used to model a water dehydration membrane module and a tubular reactor in Aspen Custom Modeler including their design aspects. These custom models were used afterwards as add-ins in Aspen Plus for detailed process calculations and evaluation.

\section{GOVERNING EQUATIONS \\ Reaction kinetics}

The reaction under consideration is the acetalization of ethanol (A) and butanal (B) to produce 1,1-diethoxy butane (C) and water (D):

$$
\begin{gathered}
2 \mathrm{C}_{2} \mathrm{H}_{6} \mathrm{O}(\mathrm{A})+\mathrm{C}_{4} \mathrm{H}_{8} \mathrm{O}(\mathrm{B}) \Leftrightarrow \mathrm{C}_{8} \mathrm{H}_{18} \mathrm{O}_{2}(\mathrm{C})+\mathrm{H}_{2} \mathrm{O}(\mathrm{D}) \\
\Delta H_{r}^{25^{\circ} \mathrm{C}}=-31 \mathrm{~kJ} / \mathrm{mol}
\end{gathered}
$$

Like most of the acetalization reactions, this reaction is exothermic with low equilibrium conversions to 1,1-diethoxy butane, typically in range of 40 to $50 \%$ between 40 and $60^{\circ} \mathrm{C} .33$ The equilibrium conversion is higher at lower temperatures while pressure has no or only minor influence on the conversion. Acidic ion exchange resins catalyze the reaction and a pseudo-homogeneous kinetic model (Equation (1)) can describe accurately the reaction progress.

$$
\frac{d C_{i}}{d t}=\left(v_{i} w k_{1} C_{A}^{2} C_{B}-v_{i} w k_{2} C_{C} C_{D}\right) \cdot 3600
$$

For all simulations conventional plug flow tubular reactors were used with the following design equation:

$$
\frac{d F_{i}}{d z}=L A_{t}\left(v_{i} w k_{1} F_{A}^{2} F_{B} \frac{1}{v^{3}}+v_{i} w k_{2} F_{C} F_{D} \frac{1}{v^{2}}\right) \cdot 3600
$$

\section{Membrane transport}

The transport equation for a certain component through the membrane is described by Fick's Law, given by the relation ${ }^{34,35}$

$$
f_{i}=Q_{i}\left(x_{i} \gamma_{i} P_{i}^{s a t}-y_{i} P^{p e r m}\right)
$$

The saturation pressure $P_{i}^{\text {sat }}$ of each component was calculated with Antoine's equations. ${ }^{36}$ Activity coefficients were calculated with the UNIFAC thermodynamic model for ethanol/butanal/1,1diethoxy butane/water mixtures. This method has been used, as consistent VLE data of 1,1-diethoxy butane with other components are not available in the open literature. For these cases, UNIFAC is the recommended method and a more detailed discussion on this topic is provided by Prausnitz. ${ }^{36}$ This relation (3) shows that the pressure on the feed side of the membrane has no effect on the flux, while the temperature influences the saturation pressure, and therefore the flux across the membrane. At higher temperatures the saturation pressure in relation (3) increases and thus the fluxes are higher, and this leads to a lower membrane area required for the separation. Previously, the validity of using an Arrhenius type equation to describe the permeance values was confirmed, and the corresponding activation energies can be obtained by fitting experimental data within the conditions under study in the present work. $^{28}$

\section{Pervaporation module modeling}

A multi-tubular pervaporation module was chosen to simulate the water removal from the mixture. This design is similar to shell and tube heat exchangers, where membrane tubes replace the pipes through which the heat transfer occurs. The following assumptions are made in the modeling of such a pervaporation module:

- The selective membrane layer is on the outside (shell side) of the membrane tube.

- The membrane is inert and does not influence the reaction.

- Concentration-polarization and temperature-polarization are negligible.

- The permeate side is perfectly mixed.

- Permeance values depend only on the temperature, and not on the composition of the mixture.

Based on the above assumptions, the governing equations of multi-tubular pervaporation module are given by relations (4) and (5). These relations account for the mass balance for each component (4) and the energy balance (5).

$$
\frac{d F_{i}}{d z}=-L f_{i} p_{m}
$$

The pervaporation module was operated as an adiabatic system, which is at an industrial scale more common than isothermal systems. The evaporation during pervaporation requires energy and reduces the feed temperature. For these reason an energy balance is required in order to get the temperature profile along the pervaporation module (5).

$$
\frac{d T}{d z}=\frac{-L N \pi d_{0}\left(J\left|\bar{\lambda}_{i}(T)\right|\right)}{\sum\left(F_{i} C_{p, i}\right)}
$$

The pressure drop was considered negligible in the pervaporation module. In the case of tubular reactors, the pressure drop through the packed catalyst beds was accounted for through the Ergun equation:

$$
\frac{d P_{F}}{d z}=L\left[\frac{150 \mu(1-\varepsilon)^{2} v_{s}}{\phi \varepsilon^{3} d_{p}^{2}}+\frac{1.75(1-\varepsilon) v_{s}^{2} \rho}{\phi \varepsilon^{3} d_{p}}\right] \cdot 10^{-5}
$$

\section{Hydrodynamics}

In the current model, concentration and temperature polarization effects are not taken into account. The validity of these assumptions has been proven by the batch reactor analyses. Comparison between experimental data and modeling predictions showed fairly good agreement. ${ }^{28}$ This is in agreement with the findings by Sommer ${ }^{37}$ who found a limited influence of polarization effects. The origin of the concentration polarization can be found in the selective transport of water through the membrane. As a result the water may be depleted from the bulk towards the membrane. ${ }^{37}$ Temperature polarization is a 


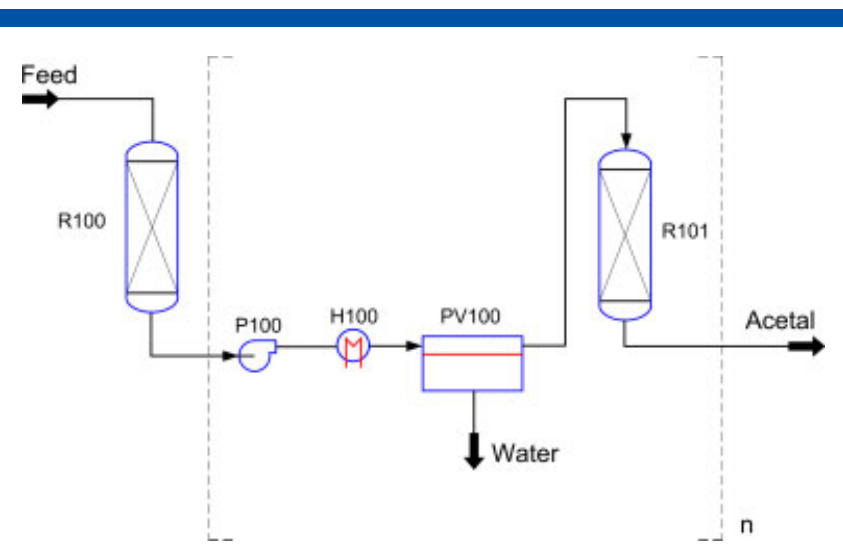

Figure 1. Flow sheet diagram of PFR and PV modules in series.

consequence of the evaporation that occurs over the membrane. The necessary vaporization enthalpy is taken from the energy of bulk fluid on the feed/retentate side decreasing the mixture temperature towards the membrane surface. Further precautions have been taken to limit the possible effects. In a laminar flow regime and at high membrane permeances polarization effects can be significant resulting in decreased pervaporation efficiency. Sommer et al. ${ }^{37}$ concluded that, for an annular duct module type, there is a steep efficiency increase at Reynolds $=2300$ (transition between laminar and turbulent flow regime). For this reason the feed will be kept in the transition flow regime throughout the current study. In our case, this means that the actual module efficiency is $\sim 90 \%$, leading to an acceptable small underestimation of the membrane area needed. In the present case, as a multitube module was considered the transition flow regime limits are between $R e=20$ and $100 .{ }^{38,39}$ In these cases the outer diameter of the membrane tubes must be used for Re calculations

$$
\operatorname{Re}=\frac{d_{0} v \rho}{\mu}
$$

The module design was based on the shell-and-tube heat exchangers using the equilateral triangular layout, the one that offers the highest membrane area to volume ratio. The typical pitch distance of 1.25 times the pipe diameter ${ }^{38}$ was used. Thus, the membrane module used to treat a feed flow rate of $7 \mathrm{~L} \mathrm{~h}^{-1}$ was based on 43 tubes with a diameter of $3 \mathrm{~mm}$ and a module shell diameter of $30 \mathrm{~mm}$, as the most promising configuration.

\section{UN-COUPLED PROCESS ALTERNATIVES}

Based upon the process analysis, three different process designs based on adiabatic tubular reactors and adiabatic pervaporation modules have been set up and evaluated:

i) reactor and pervaporation in series (Fig. 1);

ii) reactor and pervaporation including a recycle loop (Fig. 2);

iii) reactor, pervaporation and a distillation column recycling the top stream of the distillation (Fig. 3).

In these cases no catalyst particles are present between the membrane tubes as the reactor and membrane separator are physically separated. As a result, the ratio between the membrane area and the shell side volume can be much higher and the water removal by pervaporation is more efficient than in the case of a multi-tube plug flow membrane reactor (MPFMR). A detailed analysis of the three configurations using Aspen flow sheeting will be presented.

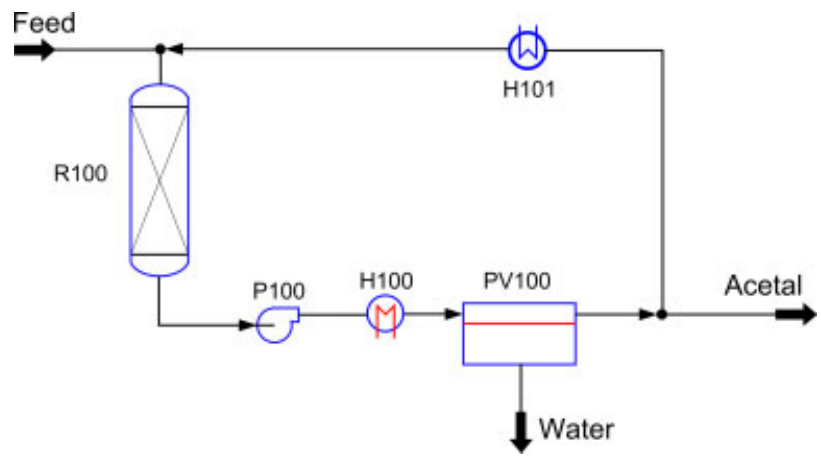

Figure 2. Flow sheet diagram of reactor and pervaporation with recycling loop.

\section{Reactor and pervaporation in series}

Initially the optimum number of adiabatic plug flow reactors (PFR) and pervaporation modules (PV) placed in series as shown in Fig. 1 was estimated. The feed of the first reactor was set at $25^{\circ} \mathrm{C}$. After each reactor a liquid pump was placed to compensate for the pressure drop in the reactor. This was followed by a heat exchanger to increase the inlet temperature of the mixture to the pervaporation unit to its boiling point of around $80^{\circ} \mathrm{C}$. During the pervaporation operation the temperature decreased and the cooled retentate stream was led to the next reactor. It should be noted that a lower temperature leads to higher conversions and is thus beneficial for the following reactor. The membrane area of each pervaporation module was optimized. For that purpose the module length was varied keeping the module diameter constant and membrane configuration as explained earlier in order to have a suitable flow regime. The module length was chosen after observing the decreasing curve of the driving force in each case. The main results are presented in Table 1.

Table 1 shows that the conversion increases with the number of reactors/pervaporators in series. With five PFR reactors and four PV modules $(n=4)$ and a total membrane area of $1 \mathrm{~m}^{2}$ in series, the achieved maximum conversion was $71.2 \%$, which is comparable with the experimental conversions achieved in semibatch mode. ${ }^{28}$ However, the increase in the conversion after three reactors is limited and it does not make sense to have more than four PV modules. Based upon these results some observations can be made:

- The first PV100 module was much larger than the other modules; the value for $A_{m}$ reduces from $0.45 \mathrm{~m}^{2}$ for the first PV module to $0.10 \mathrm{~m}^{2}$ for the fourth module. The reason is that in the first module a large amount of water had to be separated resulting in a large temperature drop, reducing the driving force at the end of the module and thus the flux. Higher water outlet content would give a lower membrane area but could lead to limitations for R101.

- The inlet temperature in the reactors R103 and R104 was rather high and a small cooler could improve the conversion of this reactor. This cooler could be heat integrated with a heat exchanger H100n. This could also lead to lower operating costs.

- The ethanol to butanal feed ratio in the first reactor was the stoichiometric ratio of $2: 1$. In the other reactors this ratio gradually decreases as some ethanol permeates through the membrane. Adding some extra ethanol, e.g. before reactor R103, would help shift the equilibrium further. 


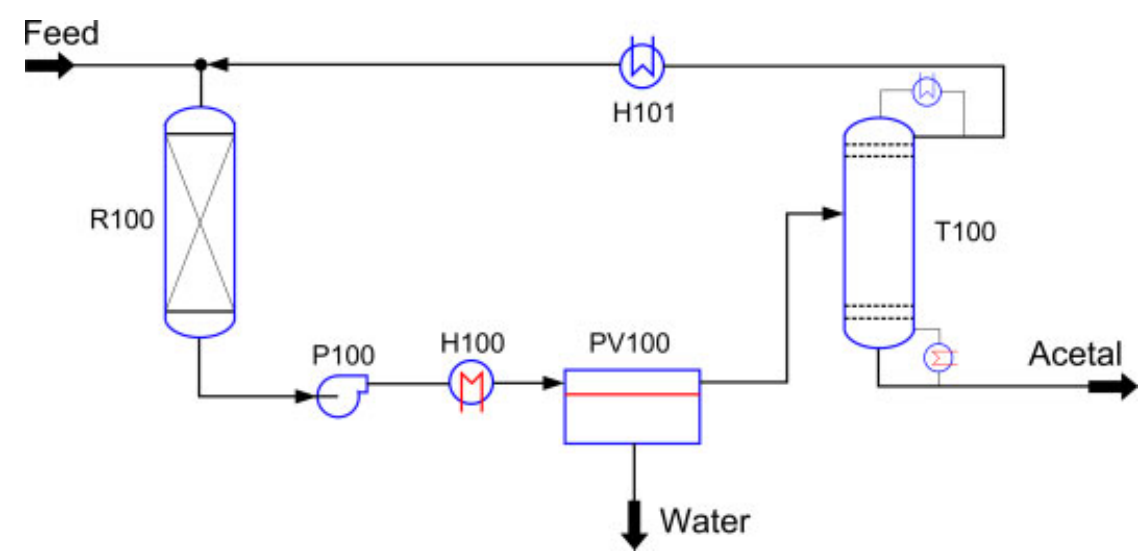

Figure 3. Flow sheet diagram of the process including a distillation column and a recycle loop.

\begin{tabular}{|c|c|c|c|c|c|c|c|c|c|}
\hline & \multicolumn{2}{|c|}{ R100/PV100 } & \multicolumn{2}{|c|}{ R101/PV101 } & \multicolumn{2}{|c|}{ R102/PV102 } & \multicolumn{2}{|c|}{ R103/PV103 } & R104 \\
\hline $\mathrm{R}_{\mathrm{v}}, \mathrm{dm}^{3} / \mathrm{A}_{\mathrm{m}}, \mathrm{m}^{2}$ (reactor vol./mem. area) & \multicolumn{2}{|c|}{$0.053 / 0.45$} & \multicolumn{2}{|c|}{$0.088 / 0.24$} & \multicolumn{2}{|c|}{$0.044 / 0.20$} & \multicolumn{2}{|c|}{$0.027 / 0.10$} & 0.008 \\
\hline$X \% / \theta, \%$ (conversion/water cut) & \multicolumn{2}{|c|}{$45.8 / 85.8$} & \multicolumn{2}{|c|}{$60.3 / 92.4$} & \multicolumn{2}{|c|}{$66.3 / 93.6$} & \multicolumn{2}{|c|}{$69.3 / 91.2$} & 71.2 \\
\hline Re range & \multicolumn{2}{|c|}{$13-21 / 14-28$} & \multicolumn{2}{|c|}{$13-16 / 18-26$} & \multicolumn{2}{|c|}{$17-18 / 21-25$} & \multicolumn{2}{|c|}{$19-20 / 22-25$} & $19-20$ \\
\hline $\mathrm{T}_{\text {in }},{ }^{\circ} \mathrm{C}$ & \multicolumn{2}{|c|}{$25 / 76.6$} & \multicolumn{2}{|c|}{$33.1 / 78.6$} & \multicolumn{2}{|c|}{$54.0 / 81.4$} & \multicolumn{2}{|c|}{ 69.7/83.1 } & 76.8 \\
\hline $\mathrm{T}_{\text {out }},{ }^{\circ} \mathrm{C}$ & \multicolumn{2}{|c|}{$60.7 / 33.1$} & \multicolumn{2}{|c|}{$46.5 / 54.0$} & \multicolumn{2}{|c|}{$59.9 / 69.7$} & \multicolumn{2}{|c|}{$72.8 / 76.8$} & 78.8 \\
\hline \multicolumn{10}{|l|}{ Outlet composition, mol fr. } \\
\hline ethanol & 0.433 & 0.505 & 0.397 & 0.430 & 0.376 & 0.377 & 0.347 & 0.342 & 0.322 \\
\hline butanal & 0.211 & 0.252 & 0.197 & 0.222 & 0.195 & 0.208 & 0.193 & 0.201 & 0.191 \\
\hline acetal & 0.178 & 0.213 & 0.301 & 0.339 & 0.385 & 0.411 & 0.438 & 0.455 & 0.473 \\
\hline water & 0.178 & 0.030 & 0.105 & 0.009 & 0.044 & 0.003 & 0.022 & 0.002 & 0.014 \\
\hline
\end{tabular}

The maximum conversion is about $71 \%$, which is much higher than the equilibrium conversion of $38 \%$. The reason that the conversion does not increase to, say, $90 \%$ is the fact that the acetal concentration is increasing further and further in each step thus limiting the equilibrium of the reactor. In the end this configuration thus shows a similar performance to a batch reactor. The advantage of this configuration, when compared with combined reactor and separator in one unit, ${ }^{32}$ is a more suitable catalyst to membrane area ratio, a more flexible design and a lower pressure drop. In the membrane reactor of combined reaction and separation, the presence of catalyst particles between membrane tubes leads to large separation distances between membrane tubes in order to avoid wall effects and therefore unrealistic unit dimensions. However, in both cases the flow regime was the same, always above the laminar flow regime limit. The configuration in series leads to a shorter reactor and pervaporation membrane to achieve the same conversion (Table 2). However, this configuration is complex and a large number of units (five reactors and four pervaporation modules) are required.

\section{Reactor and pervaporation with a recycle loop}

To reduce the number of units, a process with a recycle loop was considered. In this case only one reactor and one pervaporation module are required. It is anticipated that this would lead to lower capital expenditure. Figure 2 shows this basic process configuration.

For this configuration the influence of the recycle ratio on the reactor length and the PV module length was determined.

\begin{tabular}{|lcc|}
\hline Table 2. Sizes for unit operations in series and for MPFMR & \\
\hline Dimension & PFR+PV in series & MPFMR ${ }^{28}$ \\
\hline $\begin{array}{l}\text { Reactor length/PV module } \\
\text { length }(\mathrm{m})\end{array}$ & $1.3 / 2.45$ & 15 \\
$\begin{array}{l}\text { Reactor diameter/PV module } \\
\text { diameter }(\mathrm{mm})\end{array}$ & $15 / 30$ & 22 \\
$\begin{array}{l}\text { Catalyst volume }\left(\mathrm{dm}^{3}\right) \\
\text { Total membrane } \mathrm{area}\left(\mathrm{m}^{2}\right)\end{array}$ & 0.23 & 3.39 \\
& 1 & 0.66 \\
\hline
\end{tabular}

By increasing the recycle ratio, this being the ratio between the recycle molar flow and the retentate molar flow, the flow rate in the reactor increases. Thus, the residence time decreases and longer reactors and membrane modules are required in order to end up with the same water cut $(\theta)$ and conversion values as in the previous case. In addition, also the plug flow reactor diameter to length ratio was modified for each recycle ratio in order to avoid extremely high pressure drops.

The simulations show that conversions of $65-68 \%$ can be reached at a very high recycle ratio of $0.8-0.9$. At high recycle ratios, the flow and the Re numbers in the reactor and pervaporation module increase rapidly and the diameter/length ratio was varied to keep the simulations in similar flow regimes. As a result these units become larger. The shell diameter of the pervaporation module had to be increased from 0.03 to $0.07 \mathrm{~m}$. At the same time the membrane area increased to $1.6 \mathrm{~m}^{2}$ to achieve $71 \%$ conversion. This value is also comparable with 
the maximum conversion achieved experimentally in a batch membrane reactor. ${ }^{28}$

\section{Reactor, pervaporation and distillation with a recycle of the top stream}

Both configurations presented above require a relatively large membrane surface area to fulfill all the hydrodynamic constraints and to achieve high conversion. In an attempt to reduce this, a last process configuration was designed in which the splitter of the previous process was replaced by a distillation column. The use of a distillation column will lead to higher operating and capital costs because of the energy demand of the reboiler and the higher investment in the column compared with a simple splitter. An economic benefit is still anticipated, as only the non-reacted reactants are recycled to the reactor and an overall conversion of $100 \%$ can be achieved. Pure acetal leaves the column at the bottom. As result the concentration of the reactants will be higher and overall conversion of 1,1-diethoxy butane will increase. In addition, the flow rate through the system will be lower and this will lead to smaller equipment. The process configuration is shown in Fig. 3.

As before and for the same reasons, a liquid pump and a heat exchanger are placed between the reactor and the pervaporation module. This arrangement ensures optimal utilization of the membrane at minimum surface area. Thus, the required membrane area is $0.81 \mathrm{~m}^{2}, 20 \%$ and $50 \%$ less than in the previously explained options.

The added value of this arrangement is that the absence of water simplifies the distillation process dramatically. For the separation of acetal via distillation from ethanol and butanal only six theoretical trays (incl. condenser and reboiler) are required to reach 99.99 mol\% purity and a recovery of $99 \%$. When water is not removed prior to the distillation, a complex process with at least two columns and with many trays is required. This can be attributed to the existence of azeotropes that water forms with all components. Table $3 \mathrm{a}$ and $3 \mathrm{~b}$ presents the main dimensions and results of the calculations. The number of stages and the feed stage of the simple distillation column presented in Table $3 \mathrm{~b}$ was found minimizing the reboiler (and condenser) heat duties for the above mentioned specifications. A tray efficiency of 0.6 was applied.

\section{Selection of the most promising alternative}

Comparison of the three process schemes and the multi-tube plug flow membrane reactor (MPFMR) (Table 4), shows that the removal of water alone either by a series or recycle system leads to conversions similar to those observed experimentally in a batch system. ${ }^{28}$ These configurations require a relatively large membrane area or an unrealistic design. The membrane reactor (MPFMR) requires the least membrane area but due to the design constraints generated by the presence of the catalyst, the length of the reactor to treat $7 \mathrm{~L} \mathrm{~h}^{-1}$ is unrealistic. ${ }^{32}$ The last configuration in which almost pure ethanol and butanal is recycled results in a process conversion of almost $100 \%$. This high conversion is anticipated to compensate for the additional energy requirement of the distillation column. Anyhow, the series and recycle loop options do need extra (downstream) separation as the acetal is not pure. Also the required membrane surface area of $0.81 \mathrm{~m}^{2}$ is anticipated to be reasonable. On the basis of these considerations the configuration of a tubular reactor, a pervaporation module and a distillation column was selected for more detailed evaluation and comparison with the base case process and a reactive distillation process.
Table 3a. Process parameters in the reactor and pervaporation module (see Fig. 3). 'Reactor, pervaporation and distillation' process configuration

\begin{tabular}{|c|c|c|c|}
\hline \multicolumn{2}{|l|}{ Reactor (R100) } & \multicolumn{2}{|c|}{ Pervaporation unit (PV100) } \\
\hline Inlet flow, $\mathrm{Lh}^{-1 \mathrm{a}}$ & 15.9 & Inlet flow $L h^{-1}$ & 15.9 \\
\hline $\begin{array}{l}\text { Inlet molar flow rate, } \\
\mathrm{kmol} \mathrm{h}^{-1}\end{array}$ & 0.17 & $\begin{array}{l}\text { Inlet molar flow rate, } \\
\mathrm{kmol} \mathrm{h}^{-1}\end{array}$ & 0.15 \\
\hline Re range & $11-17$ & Re range & $40-0$ \\
\hline$T_{\text {in }} / T_{\text {out }},{ }^{\circ} \mathrm{C}$ & $25 / 58$ & $T_{\text {in }} / T_{\text {out }},{ }^{\circ} \mathrm{C}$ & $80 / 36$ \\
\hline Volume, $\mathrm{dm}^{3}$ & 0.12 & Membrane area, $\mathrm{m}^{2}$ & 0.81 \\
\hline \multirow{2}{*}{$\chi, \%$} & 43.5 & $\theta, \%$ & 79.4 \\
\hline & & $\begin{array}{l}\text { Permeate pressure, } \\
\text { mbar }\end{array}$ & 5 \\
\hline Outlet comp, mol fr. & & Outlet comp, mol fr. & \\
\hline Ethanol & 0.167 & Ethanol & 0.200 \\
\hline Butanal & 0.208 & Butanal & 0.249 \\
\hline Acetal & 0.424 & Acetal & 0.501 \\
\hline Water & 0.201 & Water & 0.050 \\
\hline
\end{tabular}

Table 3b. Process parameters in the distillation column (see Fig. 3). 'Reactor, pervaporation and distillation' process configuration

Distillation column (T100)

Condenser duty, kW $-1.73$

Reboiler duty, kW 2.23

Real stages (incl. reb. \& cond.)

Feed stage*

Recycle ratio

0.22

Distillate to feed molar ratio 0.81

Temperature top/bottom, ${ }^{\circ} \mathrm{C}$ $74.1 / 119.5$

Inlet molar flow rate, $\mathrm{kmol}^{-1}$

0.12

\begin{tabular}{lcc} 
& Top & Bottom \\
Outlet molar flow rate, $\mathrm{kmol} \mathrm{h}^{-1}$ & 0.10 & 0.02 \\
Outlet comp., mol fr. & & \\
Ethanol & 0.620 & 0 \\
Butanal & 0.309 & 0 \\
Acetal & 0.010 & 0.999 \\
Water & 0.061 & 0.001 \\
\hline * The head of the column, the condenser, is considered the first stage.
\end{tabular}

\section{FULL-SCALE PROCESS COMPARISON}

In the above section it is shown that the use of dehydration membranes can facilitate the acetal production process. However, it is necessary to know if this process can compete with other alternatives, from the economic point of view. Therefore, in this section three conceptual process designs for a full-scale industrial acetal production process are compared:

i) conventional tubular reactor followed by a distillation train (base case);

ii) reactive distillation;

iii) conventional tubular reactor followed by a pervaporation step and a distillation column.

With the information gathered in the process development simulations (material and energy balances) the different unit 
Table 4. Comparison of the developed processes with membranes (treated fresh feed: $7 \mathrm{~L} \mathrm{~h}^{-1}$ )

\begin{tabular}{lcccc|}
$\begin{array}{l}\text { Process } \\
\text { configuration }\end{array}$ & $\begin{array}{c}\text { Conversion } \\
(\%)\end{array}$ & $\begin{array}{c}\text { Membrane } \\
\text { tubes } \\
\text { length }(\mathrm{m})\end{array}$ & $\begin{array}{c}\text { Membrane } \\
\text { area } \\
\left(\mathrm{m}^{2}\right)\end{array}$ & $\begin{array}{c}\text { Catalyst } \\
\text { volume } \\
\left(\mathrm{dm}^{3}\right)\end{array}$ \\
\hline MPFMR $^{28}$ & 74.6 & 15 & 0.66 & 3.39 \\
PFR + PV in series & 70.6 & 2.45 & 1.00 & 0.22 \\
PFR + PV + recycle & 71.0 & 0.6 & 1.60 & 2.39 \\
PFR + PV + Dist & 99.7 & 2 & 0.81 & 0.12 \\
\hline
\end{tabular}
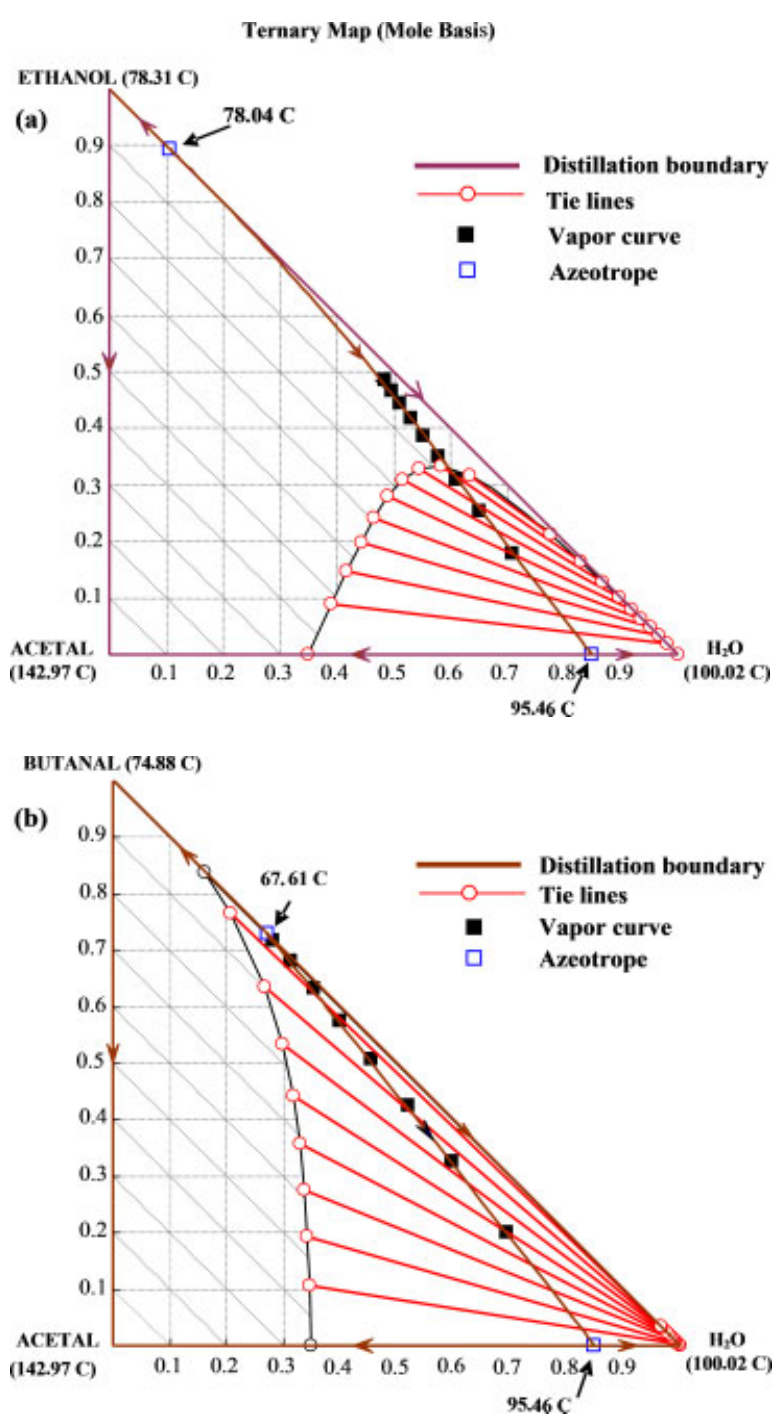

Figure 4. Vapor-liquid-liquid equilibrium diagrams for (a) ethanol-acetalwater and b) butanal-acetal-water ternary mixtures estimated by Aspen Plus.

operations are dimensioned and capital and operating costs estimated. This comparison allows for the selection of the process with the lowest costs. In all cases the production amount of acetal is set at $50 \mathrm{kt}$ acetal year $^{-1}$; this is a typical plant capacity and is comparable with the average size of an ETBE production plant. The acetal purity is set at $99.99 \mathrm{~mol} \%$ for each case.
Table 5. Azeotropes formed in the quaternary mixture. ${ }^{\text {a }}$ Estimated by Aspen, ${ }^{\text {b }}$ Kirk Othmer Encyclopedia ${ }^{40}$

\begin{tabular}{|c|c|c|c|c|c|c|}
\hline \multirow[b]{2}{*}{ Azeo. no. } & \multirow[b]{2}{*}{ Azeo. type } & $\mathrm{EtOH}$ & Butanal & Acetal & Water & \multirow{2}{*}{$\frac{\mathrm{T}_{\text {boil }}}{{ }^{\circ} \mathrm{C}}$} \\
\hline & & \multicolumn{4}{|c|}{$\mathrm{mol} \%$} & \\
\hline $1^{\mathrm{a}}$ & homogeneous & 26.2 & 73.8 & 0 & 0 & 72.5 \\
\hline $2^{\mathrm{a}}$ & homogeneous & 89.3 & 0 & 0 & 10.7 & 78.0 \\
\hline $3^{a}$ & heterogeneous & 0 & 72.8 & 0 & 27.2 & 67.6 \\
\hline $4^{a}$ & heterogeneous & 0 & 0 & 14.7 & 85.3 & 95.6 \\
\hline $5^{b}$ & heterogeneous & 12.9 & 60.1 & 0 & 27.0 & 67.2 \\
\hline
\end{tabular}

\section{Base case}

The base case consists of a 1,1-diethoxy butane production process based on conventional unit operations currently used in the process industry and is built up from a tubular reactor and conventional distillation. The conceptual design of a process requires the knowledge of the thermodynamic behavior of the system, and the appropriate system configuration is determined. Since the distillation is the separation unit, it is important to know the vapor-liquid equilibrium behavior of the components present. These diagrams, generated by Aspen Properties using UNIFAC thermodynamic package, are presented in Fig. 4, and the list of azeotropes formed is given in Table 5. In the system four azeotropes can be identified and in some regions of the ternary diagram, two liquid phases are formed.

Doherty and Malone ${ }^{41}$ is an excellent reference to the systematic design of a conceptual process flow diagram. Following the explanation in the book the process flow diagram presented in Fig. 5 was obtained. The conventional tubular reactor is followed by two distillation columns with a liquid-liquid decanter in between. The aim of the first distillation column (T100) is to remove water and acetal from the bottom. Acetal being less volatile than water will be concentrated in the bottom while butanal being more volatile than ethanol is collected at the top of the column. However, the ethanol/water azeotrope will limit this separation and part of the water will go to the top and will be recycled to the reactor. Therefore, the selected design specification for this column is ethanol recovery in the top, which is set to $0.9999 \mathrm{~mol} \mathrm{~mol}^{-1}$, so the acetal stream will not contain any ethanol. The second design specification is for water recovery at the bottom, which is set to $0.5 \mathrm{~mol} \mathrm{~mol}^{-1}$ and is limited by the ethanol/water azeotrope.

A $\sim 50 / 50 \mathrm{~mol} \%$ of water and acetal mixture leaves the bottom of $\mathrm{T} 100$ at $90^{\circ} \mathrm{C}$. Under these conditions, two liquid phases are formed, Fig. 6 . The aqueous phase is nearly $100 \%$ pure water. This thermodynamic feature of the mixture is used to separate water in decanter V100. The organic phase, containing $\sim 35 \%$ water, is dehydrated in T101. Acetal, $99.99 \%$ purity, is removed as product from the bottom while the top stream with near to azeotropic composition, $14.7 \mathrm{~mol} \%$ acetal, is recycled back to the decanter V100. The allowable acetal content in this top stream is set at $20 \mathrm{~mol} \%$. This value is near the azeotropic composition but sufficiently far away from it to avoid high reboiler (and condenser) duties. To prevent the decomposition of 1,1-diethoxy butane to 1-ethoxy-1-butene and ethanol at high reboiler temperatures, ${ }^{27}$ the column T101 was operated at sub-atmospheric pressure of 0.5 bar.

The design specifications of the industrial scale conventional process and main calculated equipment data are summarized in Table 6. 


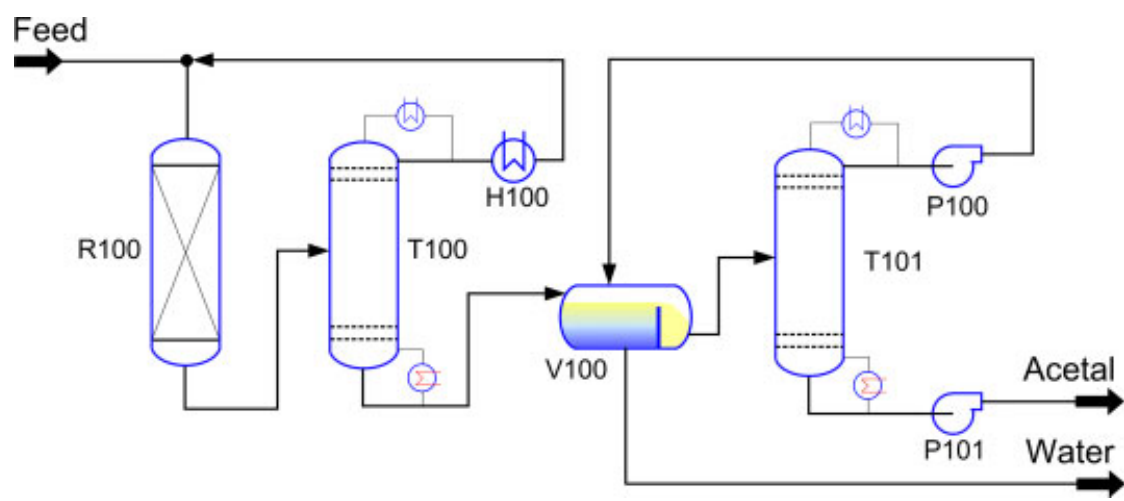

Figure 5. Process flow sheet diagram of the conventional process or the 'base case'.

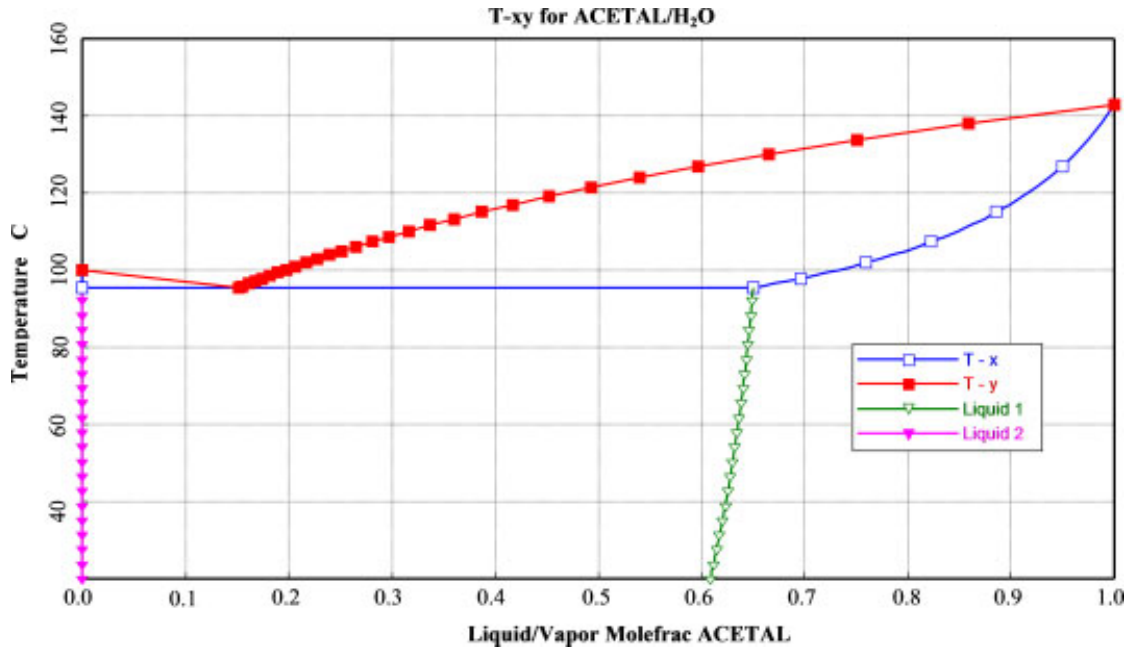

Figure 6. Vapor-liquid-liquid equilibrium of 1,1-diethoxy butane/water.

Table 6. Design specifications and calculated data for the 'base case'

\begin{tabular}{|lcc|} 
& $\begin{array}{c}\text { Distil. } \\
\text { Column 1 } \\
\text { (T100) }\end{array}$ & $\begin{array}{c}\text { Distil. } \\
\text { Column 2 } \\
\text { (T101) }\end{array}$ \\
\hline $\mathrm{H}_{2} \mathrm{O}$ recovery in the bottom, $\mathrm{mol} \mathrm{mol}^{-1}$ & 0.5 & - \\
EtOH recovery in the top, $\mathrm{mol} \mathrm{mol}^{-1}$ & 0.9999 & - \\
Acetal purity in the bottom, $\mathrm{mol} \mathrm{mol}^{-1}$ & - & 0.9999 \\
$\mathrm{H}_{2} \mathrm{O}$ composition top, $\mathrm{mol} \mathrm{mol}^{-1}$ & - & 0.8 \\
Equilibrium stages (reb \& cond. included) & 50 & 11 \\
Real stages (reb \& cond. included) & 82 & 17 \\
Feed stage & 17 & 6 \\
Reflux ratio & 1.15 & 0.5 \\
Reboiler duty, MW & 5.85 & 0.73 \\
Condenser duty, MW & 5.52 & 0.61 \\
Bottom to feed ratio & 0.26 & 0.56 \\
Pressure (column head), bar & 1 & 0.5 \\
Column diameter, $\mathrm{m}$ & 1.75 & 1 \\
Column height, $\mathrm{m}$ & 51 & 10 \\
\hline * The reactor and the decanter operate in adiabatic regime. & \\
\hline
\end{tabular}

The product yield is for this base case the highest achievable, as no reactants are lost in the product or in the by-product streams. Consequently, the overall conversion is nearly $100 \%$. Further, the
$51 \mathrm{~m}$ height of the first distillation column is within the limit of realistic column dimensions. ${ }^{42}$

\section{Reactive distillation case}

Reactive distillation has been proven to overcome thermodynamic limitations and conversions higher than those at equilibrium can be achieved. ${ }^{27}$ Still, the conversion is not complete and an additional separation train was developed to reach $99.99 \%$ product purity. The flowsheet diagram (Fig. 7) was based on the same thermodynamic property method and design constrains as in the conventional case.

The reactive distillation column configuration that meets the design constraints was found experimentally and by modeling ${ }^{27}$ and applied in Aspen Plus. Similar to the base case, two additional columns were required in addition to the reactive distillation column to reach the purity demands. The maximum achievable conversion in the reactive distillation unit itself is $50 \%{ }^{27}$ but as some water is recycled the step conversion decreases to $43 \%$. The step conversion in the tubular reactor of the base case was $39 \%$. The conversion increase using reactive distillation is thus minimal. The main reason for this small difference can be found in the higher operating temperature of the reactive distillation column. In the base case, the inlet and outlet temperature to the reactor are at $25^{\circ} \mathrm{C}$ and $56^{\circ} \mathrm{C}$, respectively. In a reactive distillation system the reaction temperature is given by the reboiler composition and therefore, reboiler temperature, being in this case $\sim 73^{\circ} \mathrm{C}$. 


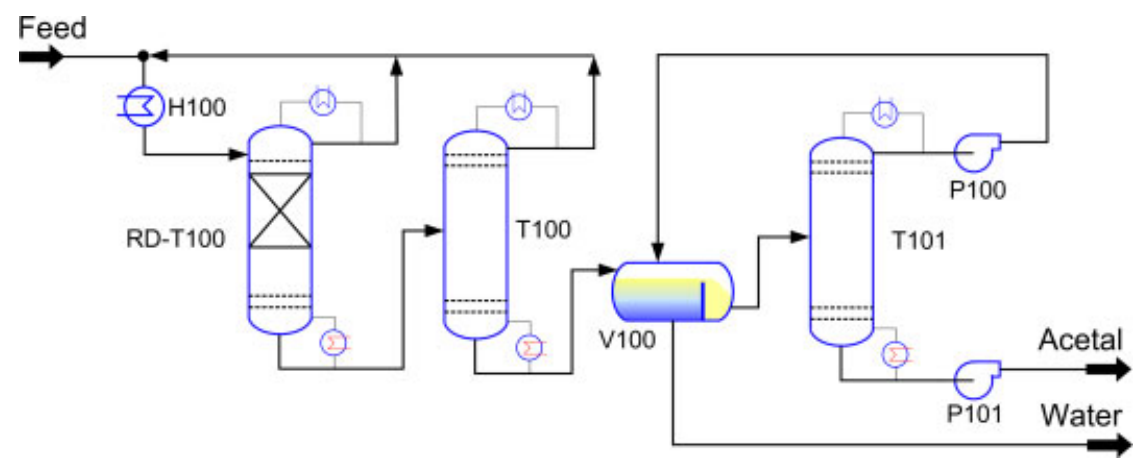

Figure 7. Process flow diagram of the reactive distillation case.

\begin{tabular}{|c|c|c|c|}
\hline & $\begin{array}{l}\text { Reactive } \\
\text { dist. } \\
\text { column } \\
\text { (RD-T100) }\end{array}$ & $\begin{array}{l}\text { Dist. } \\
\text { Column } 1 \\
\text { (T100) }\end{array}$ & $\begin{array}{l}\text { Dist. } \\
\text { Column } 2 \\
\text { (T101) }\end{array}$ \\
\hline $\begin{array}{l}\mathrm{H}_{2} \mathrm{O} \text { recovery bottoms, } \\
\mathrm{mol} \mathrm{mol}^{-1}\end{array}$ & - & 0.8 & - \\
\hline $\begin{array}{l}\text { EtOH recovery top, } \\
\qquad \mathrm{mol} \mathrm{mol}^{-1}\end{array}$ & - & 0.9999 & - \\
\hline $\begin{array}{l}\text { Acetal purity in the } \\
\text { bottoms, } \mathrm{mol} \mathrm{mol}^{-1}\end{array}$ & - & - & 0.9999 \\
\hline $\begin{array}{l}\mathrm{H}_{2} \mathrm{O} \text { composition top, } \\
\mathrm{mol} \mathrm{mol}^{-1}\end{array}$ & - & - & 0.8 \\
\hline $\begin{array}{l}\text { Equilibrium stages (reb \& } \\
\text { cond. Included) }\end{array}$ & 8 & 50 & 11 \\
\hline $\begin{array}{l}\text { Real stages (reb \& cond. } \\
\text { Included) }\end{array}$ & 12 & 82 & 17 \\
\hline Feed stage & 2 & 7 & 6 \\
\hline Reflux ratio & 5 & 5.98 & 0.5 \\
\hline Reboiler duty, MW & 8.33 & 4.85 & 0.73 \\
\hline Condenser duty, MW & 8.62 & 4.84 & 0.61 \\
\hline Bottom to feed ratio & 0.45 & 0.58 & 0.56 \\
\hline $\begin{array}{l}\text { Pressure (column head), } \\
\text { bar }\end{array}$ & 1 & 1 & 0.5 \\
\hline Column diameter, m & 2 & 1.6 & 1 \\
\hline Column height, m & 10 & 51 & 10 \\
\hline
\end{tabular}

Since the reaction is exothermic, the conversion is lower at higher temperatures.

Table 7 shows the main specifications and calculated data for the reactive distillation case. It is remarkable that the utilization of a reactive distillation column does not lead to a significant change of the unit size compared with the base case. This is likely to be related to the existing azeotrope between water and ethanol.

\section{Membrane case}

The first estimations indicated that for the process option where a tubular reactor, a pervaporation module, and a distillation column are combined, Fig. 3, about $1200 \mathrm{~m}^{2}$ of membrane area is required in order to produce $50 \mathrm{kt}$ acetal year ${ }^{-1}$ and have $5 \mathrm{~mol} \%$ of water in the retentate. This amount of membrane area seems to be very high and will lead to unacceptable capital, maintenance, and membrane replacement costs. In addition, a temperature decrease of $\sim 45^{\circ} \mathrm{C}$ between the inlet and the outlet of the pervaporation module, Table $3 a$, indicates that the dehydration process could benefit from the use of an isothermal pervaporation module. Under isothermal operation at $80^{\circ} \mathrm{C}$, while keeping the permeate composition unchanged, the required membrane surface area decreases from $1200 \mathrm{~m}^{2}$ to $546 \mathrm{~m}^{2}$. In all cases the permeate pressure was kept equal to $5 \mathrm{mbar}$. To maintain the isothermal operation, an additional energy (e.g. steam) of $0.5 \mathrm{MW}$ is required. However, the price of this energy is much lower than the cost savings made due to the reduction of the membrane area. Further cost reductions are expected as it is very possible that heat of low exergetic quality is available on site of the prospective plant.

One limitation of the present process is the loss of ethanol through the membrane to the permeate side, $\sim 6 \mathrm{~mol} \%$. In practice various alternatives to recover the small amount of ethanol can be designed, including a recycle to the rectifier of the ethanol production process. In order to keep the design boundary conditions the same as in the previous processes, an additional ethanol/water distillation column has been included in the current study. This recovered ethanol containing $25 \mathrm{~mol} \%$ water is recycled to the reactor. A high composition of water, which is far from the azeotropic composition, is deliberately selected to ensure that this distillation is easy and cheap. This part of the process (not shown in Fig. 3 ) has been taken into account in the economic evaluation of this case. The design specifications and calculated results of distillation columns of this process case are shown in Table 8.

In this last case, the substitution of one distillation column by a dehydration membrane module leads to a lower energy consumption than in the base case and the reactive distillation case. Moreover, the efficient water removal through the membranes make the downstream distillation process much easier since water forms an azeotrope with every component (see Table 5).

\section{Preliminary cost evaluation}

To estimate capital expenditure for building the presented alternatives, each piece of equipment is sized using the information given in the previous process calculations. The Chemical Engineering Plat Cost Index (CEPCI) value given at the end of 2009 (511.8) is used and the accuracy of the estimation is around $\pm 25 \%$. The corrosive nature of aldehydes prescribes the use of stainless steel ${ }^{42}$ and this material was selected for all parts. The Total Capital Investment evaluation is based on the bare module technique, with cost equations and bare module factors as presented by Turton et al. ${ }^{42}$ For that purpose, the CAPCOST tool developed by Turton et al. ${ }^{42}$ has been used. The price of the membrane has been estimated based on Mitsui Zeolite A membrane system cost ${ }^{43}$ which was combined 
Table 8a. Design specifications and calculated data for membrane case (reactor + pervaporation module + distillation unit)

\begin{tabular}{|lcc|} 
& $\begin{array}{c}\text { Dist. } \\
\text { Column } \\
\text { T100 }\end{array}$ & $\begin{array}{c}\text { EtOH } \\
\text { recovery } \\
\text { column }\end{array}$ \\
\hline Acetal recovery bottoms, mol mol & 0.9999 & - \\
Acetal purity in the bottoms, $\mathrm{mol} \mathrm{mol}^{-1}$ & 0.9999 & - \\
EtOH composition top, $\mathrm{mol} \mathrm{mol} \mathrm{mol}^{-1}$ & - & 0.75 \\
$\mathrm{H} 2 \mathrm{O}$ composition bottom, $\mathrm{mol} \mathrm{mol}^{-1}$ & - & 0.999 \\
Equilibrium stages (incl. reb \& cond.) & 15 & 9 \\
Feed stage & 10 & 7 \\
Reflux ratio & 0.72 & 3.3 \\
Reboiler duty, MW & 3.34 & 0.27 \\
Condenser duty, MW & 3.38 & 0.16 \\
Bottom to feed ratio & 0.19 & 0.93 \\
Pressure (column head), bar & 0.5 & 1 \\
Column diameter, $\mathrm{m}$ & 2.1 & 0.3 \\
Column height, $\mathrm{m}$ & 16 & 8 \\
\hline
\end{tabular}

* The design specification in the pervaporation module was $5 \%$ water $(\mathrm{mol})$ in the retentate

Table 8b. Process parameters in the reactor and pervaporation module (see Fig. 3). 'membrane case' (reactor + pervaporation module + distillation unit)

\begin{tabular}{|c|c|c|c|}
\hline \multicolumn{2}{|l|}{ Reactor data (R100) } & \multicolumn{2}{|c|}{ Pervaporation Data (PV100) } \\
\hline Inlet flow, $\mathrm{m}^{3} \mathrm{~h}^{-1}$ & 21.2 & Inlet $\mathrm{m}^{3} \mathrm{~h}^{-1}$ & 21.2 \\
\hline $\begin{array}{l}\text { Inlet molar flow rate, } \\
\mathrm{kmol} \mathrm{h}^{-1}\end{array}$ & 318.4 & $\begin{array}{l}\text { Inlet molar flow rate, } \\
\mathrm{kmol} \mathrm{h}^{-1}\end{array}$ & 275.0 \\
\hline $\mathrm{T}_{\text {in }} / \mathrm{T}_{\text {out }},{ }^{\circ} \mathrm{C}$ & $25.5 / 61.3$ & $\mathrm{~T},{ }^{\circ} \mathrm{C}$ & 80 \\
\hline Volume, $\mathrm{dm}^{3}$ & 137 & Membrane area, $\mathrm{m}^{2}$ & 546 \\
\hline \multirow[t]{2}{*}{$\chi, \%$} & 41.0 & $\theta, \%$ & 79.4 \\
\hline & & Duty, MW & 0.5 \\
\hline Outlet comp, mol fr. & & $\begin{array}{l}\text { Outlet comp, mol fr. } \\
\text { (retentate/permeate) }\end{array}$ & \\
\hline Ethanol & 0.41 & Ethanol & $0.48 / 0.06$ \\
\hline Butanal & 0.23 & Butanal & $0.28 / 0.00$ \\
\hline Acetal & 0.16 & Acetal & $0.19 / 0.00$ \\
\hline Water & 0.20 & Water & $0.05 / 0.94$ \\
\hline
\end{tabular}

with the price of a module without membranes of a basic shell and tube heat exchanger derived from the Dutch Association of Cost Engineers ${ }^{44}$.

Previous process calculations allowed the calculation of different material and energy balances involved in each process and therefore, the operating cost could be estimated. The only operating costs that will be compared are the utility costs, these being cooling water, refrigerant fluid and steam for heating. For the 'membranes case', membrane replacement every 3 years has been taken into account as well. Good functioning during this period of time has been proven for HybSi membranes at lab scale at the much higher temperature of $150^{\circ} \mathrm{C} .{ }^{30}$ This period of time can vary depending on the membranes used. However, it is expected that in all the cases this period will increase for new generations of membranes and therefore, the influence of the membrane replacement costs will decrease in the overall process costs. The raw material costs, for ethanol and butanal, have been taken to be the same for all three cases, as the feed flow rates and
Table 9. Utility and raw material prices

$\begin{array}{lc}\text { Cooling water } & \\ \text { Low pressure steam }\left(50 \text { psig }-147.5^{\circ} \mathrm{C}\right)^{1} & 0.64 € \mathrm{t}^{-1} \\ \text { Electric power } & 30 € \mathrm{t}^{\mathrm{a}} \\ \text { Ethanol 99\% } & 0.038 €(\mathrm{~kW} \mathrm{~h})^{-1} \\ \text { Butanal 99\% } & 0.50 € \mathrm{~L}^{-1} \\ & 0.75 € \mathrm{~L}^{-1} \\ \text { a Supplied by PETRONOR (GROUP REPSOL), June } 2010 \\ \text { b Supplied by RYTTSA }\end{array}$

conditions are identical. The costs of the reactants are anticipated to be significant and were also estimated. Other operating costs, like maintenance, overhead, sales, etc., are assumed to be the same for each case and were not included in the economic evaluation.

The utility prices were provided by PETRONOR (Group REPSOL YPF) and the price of ethanol was given by RYTTSA/REPSOL. For butanal, no large-scale producer was found, and a commercial cost price was calculated based on the high-purity lab-scale ethanol-butanal price ratio. Depending on the commercial brand this ratio varies from 1 to 1.8 , and here a ratio of 1.5 was used. The cost prices for utility and raw material are given in Table 9.

For permeate condensation in the 'membranes case', a cooling system is used which requires an external refrigeration cycle to provide cooling media with a temperature of $-3.5^{\circ} \mathrm{C}$. This cycle uses electricity and for easiness of calculation a Coefficient of Performance (COP) of 4 is used. ${ }^{43}$ Table 10 shows that there is a large difference in utility costs, and thus the energy consumption between the three options. Relative to the base case, reactive distillation has utility costs that has increased by a factor of 2.5. The pervaporation case has a much lower energy consumption leading to a $\sim 40 \%$ energy cost reduction. However, the processing costs are low compared with the costs of the raw materials. Membrane replacement accounts for less than $10 \%$ of the processing costs.

The energy costs of the pervaporation case are the lowest, but the capital investment is the highest at almost double that of the base case (Table 11). The pervaporation unit dominates, with $\sim 75 \%$ of the total investment costs. The costs of the membranes are estimated to be $\sim 0.6 \mathrm{M} €$. The investment could be drastically reduced if the pervaporation process could be performed at a higher temperature as the required surface area would be much reduced. However, it is known that the acetal under investigation here is not stable at these temperatures when its concentration is above $80 \%(\mathrm{~mol}){ }^{27} \mathrm{~A}$ cheaper membrane system is required to reduce the investment costs. Recalculating the total cost of producing $1 \mathrm{~L}$ of acetal it is found that the reactive distillation is $\sim 10 \%$ more expensive than the base case. The main reason for this is, contrary to our expectation, the high energy consumption, and relatively high capital investment. The pervaporation and the base cases are almost identical in costs. The pervaporation case has lower energy costs but a higher investment. Considering that the energy price is continuously increasing, and the potential to reduce the membrane costs, one can conclude that the pervaporation process is, economically, the most viable in the long run.

Table 11 shows that the utility costs do not represent a high cost in terms of $€ \mathrm{~L}^{-1}$ but the utilization of the pervaporation case leads to a reduction of $40 \%$ in these costs. The major component of the acetal price is the costs of the raw materials, and not that of the technology and utilities. Thus, for this specific specialty chemical the savings could be lower than the uncertainty in pricing of the raw materials. However, any fluctuation in the raw material 
Table 10. Operating costs of each process

\begin{tabular}{|c|c|c|c|c|c|c|c|c|}
\hline \multirow[b]{2}{*}{ Process case } & \multicolumn{3}{|c|}{ Utility cost $\left(M € y^{-1}\right)$} & \multirow[b]{2}{*}{ Total } & \multicolumn{3}{|c|}{ Raw materials cost $\left(M € y^{-1}\right)$} & \multirow[b]{2}{*}{ Total $\left(\mathrm{M} € \mathrm{y}^{-1}\right)$} \\
\hline & Cooling & Heating & $\mathrm{MR}$ & & Ethanol & Butanal & Total & \\
\hline Conventional case & 1.08 & 2.70 & 0 & 3.78 & 20.2 & 23.4 & 43.6 & 47.38 \\
\hline Reactive distillation case & 2.61 & 5.89 & 0 & 8.50 & 20.2 & 23.4 & 43.6 & 52.10 \\
\hline Pervaporation case & 0.66 & 1.68 & 0.19 & 2.53 & 20.2 & 23.4 & 43.6 & 46.13 \\
\hline
\end{tabular}

Table 11. Consumption and costs for each process

\begin{tabular}{lccc} 
Process & Conventional & Reactive distillation & Pervaporation membrane \\
\hline Steam at 3.5 bar, $\mathrm{kg}_{\text {steam }} / \mathrm{kg}_{\text {acetal }}$ & 1.80 & 3.76 & 1.12 \\
Cooling water, $\mathrm{kgH}_{\text {H2O }} / \mathrm{kg}_{\text {acetal }}$ & 33.68 & 78.20 & 19.51 \\
Electricity, $\mathrm{kW} \cdot \mathrm{h} / \mathrm{kg}_{\text {acetal }}$ & 0 & 0 & 0.09 \\
Total capital investment, $\mathrm{M} €$ & 2.01 & 2.85 & 3.76 \\
Total utility costs, $\mathrm{M} \mathrm{y}^{-1}$ & 3.78 & 8.50 & $\mathbf{0 . 5 3}$ \\
Total utility costs, $€ \mathrm{~L}^{-\mathbf{1}}$ & $\mathbf{0 . 0 7}$ & $\mathbf{0 . 1 4}$ & $\mathbf{0 . 0 4}$ \\
Total raw material cost, $€ \mathrm{~L}^{-1}$ & 0.72 & 0.72 & 0.72 \\
Total production costs, $€ \mathrm{~L}^{-1}$ & 0.79 & 0.86 & 0.76 \\
\hline
\end{tabular}

price is the same for all three processes. The acetal prices, purely based on the raw material cost, is already $0.72 € \mathrm{~L}^{-1}$ and thus, this is the lowest limit of any price for 1,1-diethoxy butane (acetal). Therefore, the lowest acetal price would be achieved with the pervaporation case $\left(0.76 € \mathrm{~L}^{-1}\right)$. This price is slightly higher than the current diesel prices, which are about $0.7 € \mathrm{~L}^{-1}$ at a petrol station (www.energy.eu/\#fueltaxes 2011).

The proposed membrane based process could also be applied in some other similar processes like esterification or etherification reactions with other raw materials. Water is also a by-product in these reactions and efficient removal of it would facilitate the downstream distillation based separation processes since water forms azeotropes with many organics.

\section{CONCLUSIONS}

A model was developed and implemented in Aspen to describe the continuous production of 1,1-diethoxy butane and removal of the byproduct via a dehydration membrane and/or distillation. Three new processes where reaction and pervaporation are uncoupled were developed and evaluated in order to produce 1,1-diethoxy butane. The process in which a tubular reactor followed by a pervaporation module and a distillation column gave the most promising results. A low energy consumption of only $\sim 60 \%$ of the base case, was combined with high conversion and reduced equipment sizing. Still the capital investment requires a significant reduction to convince a potential acetal producer. The high process conversions ( $100 \%)$ were achieved because of efficient water separation in a pervaporation unit that leads to easy separation in the following distillation unit and further recycling to the reactor of only un-reacted compounds. This last process was compared with a conventional process and a reactive distillation process. The developed process in which dehydration membranes were used seems to be the most promising option because of a lower energy requirement that almost approaches the lowest possible limit. However, the utility costs do not represent a high cost in terms of $€ \mathrm{~L}^{-1}$ but the utilization of the pervaporation case leads to a reduction of $\sim 40 \%$ in these costs. The major component of the acetal price is the costs of the raw materials, and not that of the technology and utilities. This process concept would also be applicable in other similar processes based on esterification or etherification reactions. From the process point of view, efficient water removal avoids the formation of azeotropes in the downstream distillation columns facilitating the separation and reducing the column height from 51 to $16 \mathrm{~m}$. Moreover, advances in pervaporation membrane technology and modules fabrication, trying to lower the investments required in combination with increasing energy prices, will favor even a higher difference between this alternative and the other processes. Besides, some smart membrane module configurations like using a multi-step system with different permeate pressures would lead to a decrease in the price of the cooling system, as the first modules would not require really low permeate pressures.

\section{ACKNOWLEDGEMENTS}

The authors gratefully acknowledge the financial support of this work by the Spanish Ministry of Science and Innovation (ENE200912743-C04-04), the Basque Government and the University of the Basque Country (UPV/EHU).

\section{REFERENCES}

1 Capeletti MR, Balzano L, de la Puente G, Laborde M and Sedran $\mathrm{U}$, Synthesis of acetal (1,1-diethoxyethane) from ethanol and acetaldehyde over acidic catalysts. Appl Catal, A 198:L1 - L4 (2000),

2 Frusteri F, Spadaro L, Beatrice $C$ and Guido C, Oxygenated additives production for diesel engine emission improvement. Chem Eng J 134:239-245 (2007).

3 Kaufhold $\mathrm{M}$ and El-Chahawi M, Process for preparing acetaldehyde diethyl acetal. German patent 5527969, June 18 (1996).

4 Green TW, Protective Groups in Organic Synthesis. Wiley, New York (1981). 
5 Sharma MM, Some novel aspects of cationic ion-exchange resins as catalysts. React Funct Polym 26:3-23 (1995).

6 Mahajani SM, Kolah AK and Sharma MM, Extractive reactions with cationic exchange resins as catalysts (acetalization of aldehydes with alcohols). React Funct Polym 28:29-38 (1995).

7 Chopade SP and Sharma MM, Acetalization of ethylene glycol with formaldehyde using cation-exchange resins as catalysts:batch versus reactive distillation. React Funct Polym 34:37-45 (1997).

8 Chopade SP and Sharma MM, Reaction of ethanol and formaldehyde : use of versatile cation-exchange resins as catalyst in batch reactors and reactive distillation columns. React Funct Polym 32:53-65 (1997).

9 Zhu Y, Minet RG and Tsotsis TT, A continuous pervaporation membrane reactor for the study of esterification reactions using a composite polymeric/ceramic membrane. Chem Eng Sci 51:4103-4113 (1996).

10 Feng $X$ and Huang RYM, Studies of a membrane reactor: esterification facilitated by pervaporation. Chem Eng Sci 51:4673-4679 (1996).

11 Lim Y, Park B, Hung F, Sahimi M and Tsotsis T, Design issues of pervaporation membrane reactors for esterification. Chem Eng Sci 57:4933-4946 (2002).

12 Domingues L, Recasens F and Larrayoz MA, Studies of a pervaporation reactor: kinetics and equilibrium shift in benzyl alcohol acetylation. Chem Eng Sci 54:1461 - 1465 (1999).

13 Benedict DJ, Parulekar SJ and Tsai SP, Esterification of lactic acid and ethanol with/without pervaporation. Ind Eng Chem Res 42:2282-2291 (2003).

14 Sanz MT and Gmehling J, Esterification of acetic acid with isopropanol coupled with pervaporation. Part I: Kinetics and pervaporation studies. Chem Eng J 123:1-8 (2006).

15 Sanz MT and Gmehling J, Esterification of acetic acid with isopropanol coupled with pervaporation. Part II: Study of a pervaporation reactor. Chem Eng J 123:9-14 (2006).

16 Saracco G and Specchia V, Catalytic inorganic membrane reactors-present experience and future opportunities. Catal Rev - Sci Eng 36:305-384 (1994).

17 Coronas J and Santamaria J, Catalytic reactors based on porous ceramic membranes. Catal Today 51:377-389 (1999).

18 Sanchez Marcano JG and Tsotsis TT, Catalytic Membrane and Membrane Reactors. Wiley, Winheim (2002).

19 Drioli E and Giorno L, Comprehensive Membrane Science and Engineering, $1^{\text {st }}$ edn. Elsevier Science, Amsterdam (2010).

20 Hazarika S, Dutta A and Dutta N, Pervaporation aided esterification of carboxylic acids with ethanol catalyzed by porcine pancreatic lipase. Biocatal Biotransform 21:101-113 (2003).

21 Izak P, Mateus NMM, Afonso CAM and Crespo JG, Enhanced esterification conversion in a room temperature ionic liquid by integrated water removal with pervaporation. Sep Purif Technol 41:141-145 (2005).

22 Wasewar K, Patidar S and Agarwal VK, Esterification of lactic acid with ethanol in a pervaporation reactor:modeling and performance study. Desalination 243:305-313 (2009).

23 Wasewar KL, Modeling of pervaporation reactor for benzyl alcohol acetylation. Int J Chem React Eng 5:A6 (2007).

24 Tanna NP and Mayadevi S, Analysis of a membrane reactor : influence of membrane characteristics and operating conditions. Int J Chem React Eng 5:A5 (2007).

25 de la Iglesia O, Mallada R, Men $\theta$ ndez M and Coronas J, Continuous zeolite membrane reactor for esterification of ethanol and acetic acid. Chem Eng J 131:35-39 (2007).
26 Nemec D and Van Gemert R, Performing esterification reactions by combining heterogeneous catalysis and pervaporation in a batch process. Ind Eng Chem Res 44:9718-9726 (2005).

27 Agirre I, Barrio VL, Güemez B, Cambra JF and Arias PL, Catalytic reactive distillation process development for 1,1 diethoxy butane production from renewable sources. Bioresource Technol 102:1289-1297 (2011).

28 Agirre I, Guemez MB, Motelica A, van Veen HM, Vente JF and Arias PL, Acetalization reaction of ethanol with butyraldehyde coupled with pervaporation. Semi-batch pervaporation studies and resistance of $\mathrm{HybSi}^{\circledR}$ membranes to catalyst impacts. J Membr Sci 371:179-188 (2011).

29 Chapman PD, Oliveira T, Livingston AG and Li K, Membranes for the dehydration of solvents by pervaporation. J Membr Sci 318:5-37 (2008).

30 van Veen HM, Rietkerk MDA, Shanahan DP, van Tuel MMA, Kreiter R, Castricum $\mathrm{HL}$, etal, Pushing membrane stability boundaries with HybSi pervaporation membranes. J Membr Sci Submitted 380:124-131 (2011).

31 Kreiter R, Rietkerk Marielle DA, Castricum HL, van Veen HM, ten Elshof JE and Vente JF, Stable hybrid silica nanosieve membranes for the dehydration of lower alcohols. ChemSusChem 2:158-160 (2009).

32 Agirre I, Güemez B, Motelica A, van Veen HM, Vente J and Arias PL, The conceptual design of a continuous pervaporation membrane reactor for the production of 1,1 diethoxy butane. AlChE J DOI:10.1002/aic.12692:2011)

33 Agirre I, Barrio VL, Güemez B, Cambra JF and Arias PL, The development of a reactive distillation process for the production of 1,1 diethoxy butane from bioalcohol: kinetic study and simulation model. Int J Chem React Eng 8:A86 (2010).

34 Baker RW, Membrane Technology and Applications, 2nd edn. Wiley, Chichester (2000).

35 Nunes SP and Peinemann KV, Membrane Technology in Chemical Industry. Wiley, Weinheim (2001).

36 Prausnitz JM, Polling BE and O'Connell JP, The Properties of Gases and Liquids, 5th edn. McGraw-Hill, New York (2007).

37 Sommer S, Klinkhammer B, Schleger M and Melin T, Performance efficiency of tubular inorganic membrane modules for pervaporation. AlChE J 51:162-177 (2005).

38 Perry RH and Green DW, Perry's Chemical Engineers' Handbook, 8th edn. McGraw-Hill, New York (2007).

39 Hewitt G.F., Heat Exchanger Design Handbook. Begell House, New York (2002)

40 Kirk-Othmer, The Kirk-Othmer Encyclopedia of Chemical Technology, 5th edn. John Wiley \& Sons, New Jersey (2007).

41 Doherty MF and Malone MF, Conceptual Design of Distillation Systems. McGraw-Hill, New York (2001).

42 Turton R, Richard C. Bailie, Wallace B. Whiting and Lyle F. Albright, Analysis, Synthesis, and Design of Chemical Processes. Prentice Hall, New Jersey (2009).

43 Van Hoof V, Van den Abeele L, Buekenhoudt A, Dotremont C and Leysen R, Economic comparison between azeotropic distillation and different hybrid systems combining distillation with pervaporation for the dehydration of isopropanol. Sep Purif Technol 37:33-49 (2004).

44 Dutch association of Cost Engineers, DACE - Pricebooklet: A publication of Reed Bussiness, 27th edn (2009). 